\title{
Parecer do caso Vale
}

\author{
Jorge Hilário Gouvêa Vieira
}

\section{Caso Vale - exclusivo}

A integra do parecer que decidiu o julgamento

O voto do presidente da Comissão de Valores Mobiliárias (CVM), Jorge Hilário Gouvêa Vieira, que funcionou como relator no processo do "caso Vale", decidiu julgamento. Com exceção de Alberto Dumortout, que votou pela absolvição de todos os envolvidos, os demais julgadores - Francisco Gros, Horácio de Mendonça Netto e Antônio Milão - praticamente seguiram o voto do presidente da CVM, condenando o presidente da Bolsa de Valores do Rio, Fernando de Carvalho. O GLOBO publica com exclusividade o voto de Jorge Hilário.

\section{Inquérito Administrativo CVM/No 004/80 Voto do relator Jorge Hilário Gouvêa Vieira}

\subsection{Questões preliminares}

As defesas apresentadas levantam cinco questões preliminares, a saber: (a) invalidade do inquérito por violar o princípio da indivisibilidade de processo disciplinar e (b) por ausência de imparcialidade da CVM e do Conselho 
Monetário Nacional, (c) a suspeição do relator do processo no Colegiado da CVM, (d) a incompetência da CVM para fiscalizar o comportamento das sociedades corretoras e impor-lhes as sanções previstas na Resolução CMN no 39/08 e (e) a existência de coisa julgada na instância administrativa.

\subsection{Natureza do processo e das funções da CVM}

As três primeiras são improcedentes porque fundadas em princípios dos Códigos do Processo Penal e do Processo Civil que são inaplicáveis a processo administrativo como o presente, mediante o qual autoridade que exerce poder de polícia apura fatos para verificar a ocorrência de infrações à legislação cuja observância tem o dever de fiscalizar, e, se for o caso, identifica responsáveis e aplica sanções administrativas.

A CVM é órgão do Poder Executivo com atribuições de polícia administrativa dos mercados de valores mobiliários. Por disposição expressa de lei, é competente para expedirnormas de regulamentaçãodesses mercados, fiscalizar a observância de todas as normas em vigor no mercado e impor sanções aos que as descumprirem. Não exerce funções judiciárias. Nesse processo não há a relação trilateral peculiar ao processo judicial, de um juiz e duas partes, mas relação bilateral, entre autoridades administrativa e administrados sob sua jurisdição. O fim do processo administrativo sancionatório é informar a própria autoridade administrativa que o conduz e assegurar oportunidade de defesa aos administrados, como meio de garantir a legalidade do ato que aplica sanção administrativa. A existência desse processo não transforma em jurisdicional o ato administrativo que decide sobre a aplicação de sanções.

A improcedência da tese da defesa fica evidente quando se considera que ela importa negar a viabilidade de função típica do poder de polícia, qual seja, a de impor sanções administrativas.

Pelas mesmas razões, é improcedente a alegação de que o Conselho Monetário Nacional, ao qual a lei comete atribuição de rever as decisões da CVM, é parcial porque um dos seus membros é o Presidente da CVM. 


\subsection{Infração de normas do mercado por servidores públicos e competência da CVM}

Alega-se ainda que os fatos objeto do inquérito revelariam descumprimento pelo Dedip, o Banco Central do Brasil e o Senhor Ministro da Fazenda, do art. 19 da Lei n⿳o 6.385/76 (sobre distribuição de emissão secundária) e da Instrução nº 08/79 da CVM (sobre criação de condições artificiais de demanda, oferta ou preço); e que, por força do princípio da indivisibilidade do processo penal, a CVM não poderia legitimamente prosseguir o inquérito sem apreciar, no mesmo processo, os atos daquelas autoridades e impor-lhes sanções.

A preliminar é improcedente porque o invocado princípio do processo penal não tem aplicação a processo administrativo sancionatório; ainda que tivesse, não ocorreu na hipótese (como referido adiante) distribuição secundária sujeita ao registro do art. 19 da Lei 6.385/76 nem infração à Instrução nº 08/79; e - de qualquer modo - a CVM não tem competência para exercer poder de polícia sobre outros órgãos administrativos federais nem - muito menos - para aplicar sanções administrativas a outras autoridades.

A CVM, apesar de autarquia, é parte da administração pública federal - organização unitária, cujos órgãos têm as atribuições definidas em lei. A competência da CVM é restrita aos fatos que ocorrem nos mercados de valores mobiliários, e sua jurisdição se exerce sobre administrados - pessoas naturais e jurídicas - e não sobre outros órgãos federais.

Daí não se infira que os demais órgãos públicos possam participar dos mercados de valores mobiliários descumprindo as normas que os regulam. Ao contrário: todo e qualquer servidor público tem o dever legal, expressamente previsto no item IV do art. 194 da Lei no 1.711/52, de observar todas as leis do País, e não apenas aquelas específicas do órgão em que se acha lotado. E se falta a esse dever, responde administrativamente e fica sujeito às sanções disciplinares do Estatuto de Funcionários Públicos.

O funcionamento ordenado da administração pública seria inviável se cada órgão pudesse impor sanções aos demais, ou a seus servidores. Por isso, e em virtude do princípio hierárquico da administração, a competência para apurar a responsabilidade administrativa de servidores públicos e impor penas disciplinares é do superior hierárquico do infrator (art. 210 da Lei no $1.711 / 52$ ), e não do órgão encarregado de fiscalizar a legislação infringida.

De acordo com esses princípios, a CVM tem o poder-dever de conhecer e apurar infrações às normas do mercado de valores mobiliários praticadas por servidores públicos que, no exercício de suas funções, participam do mercado 
vendendo ou comprando títulos; mas, verificada a ocorrência de infração, o que lhe cumpre é comunicar o fato à autoridade competente para apurar a responsabilidade do servidor, e não aplicar-lhe as sanções da legislação do mercado.

Essas considerações são suficientes para deixar evidente a incompatibilidade que existe entre o princípio da indivisibilidade - próprio do processo judiciário penal - e o processo administrativo sancionatário.

\subsection{Competência concorrente da CVM e do Conselho de Administração das Bolsas de Valores para impor sanções da Lei $n^{\circ}$ 6.385/76}

A alegação de que "o órgão competente para fiscalizar o comportamento das corretoras e aplicar sanções disciplinares previstas na própria Resolução no 39 é a Bolsa de Valores e não a CVM" (fls. 1 a 14) e de que "as decisões das Bolsas de Valores não podem ser revistas pela CVM" conflita com a letra de disposições legais e regulamentares.

A administração das Bolsas, como de qualquer outra corporação privada, exerce poder disciplinar sobre seus membros; além disso, devido à definição legal das Bolsas como órgão auxiliar da CVM, exerce funções delegadas pelo poder público, de impor a seus membros as sanções administrativas da legislação do mercado (art. 7º, VII, da Res. no 39/66). Todas as atividades das Bolsas, inclusive o exercício do poder disciplinar, estão sujeitas à regulamentação do Conselho Monetário Nacional e da CVM (art. 18 da Lei 6.385), são supervisionadas e estão sob permanente fiscalização da CVM (arts. 17 e $8^{\circ}$, III, da Lei 6.385). A delegação de competência para impor sanções a seus membros não exclui a mesma competência expressamente atribuída pela lei à CVM (art. 9º, V e VI da Lei 6.385). As duas competências são concorrentes, e a regulamentação em vigor confirma a atribuição à CVM da função revisora dos atos dos Conselhos de Administração das Bolsas que impõem sanções a seus membros (Res. 39, art. $9^{\circ}$ ).

\subsection{Inexistência de coisa julgada}

Igualmente improcedente é a alegação de que a decisão do Conselho de Administração da BVRJ criou coisa julgada administrativa. Mesmo sem 
considerar que coisa julgada é atributo de decisão judicial, ela não poderá ocorrer na hipótese, já que a função delegada ao Conselho de Administração das Bolsas não exclui a competência legal da CVM, que tem atribuições de supervisionar, fiscalizar e rever os atos das administrações das Bolsas.

Rejeito, por esses fundamentos e mais os que constam do parecer da Superintendência Jurídica, de fls. 1364 e seguintes, todas as preliminares levantadas.

\subsection{Fatos apurados e possiveis infrações às normas do mercado}

O inquérito procedido comprova dois fatos principais que devem ser apreciados do ponto de vista da legislação do mercado de valores imobiliários:

a) nos dias 5 a 11 de março, a Corretora Ney Carvalho, sem prévia informação ao mercado, nem adoção de procedimentos especiais, vendeu nas Bolsas do Rio de Janeiro e de São Paulo, por ordem do Dedip do Banco Central do Brasil (na qualidade de agente do Tesouro Nacional), uma quantidade excepcional de ações preferenciais da Cia. Vale do Rio Doce, de propriedade do Tesouro; o total vendido foi de 149.799 .000 ações, enquanto que a média diária de negociação dessas ações nos dias anteriores havia sido de 4 milhões de ações; desse total, 103.420 .000 ações foram vendidas no dia 11, ou seja, em um dia foi vendida quantidade igual a 25 vezes a média diária dos últimos 60 dias.

b) no final do pregão do dia 11 de março na BVRJ, o operador da Corretora Ney Carvalho deixou de apregoar as ações e passou a procurar colocar o maior número possível de títulos pelo valor mínimo que havia sido estabelecido pelo comitente; a esse nível de preço, a demanda da ação foi tão grande que criou tumulto insólito junto ao posto que aceitava - a preço fixo - todos os pedidos de quantos corretores dele conseguiam se aproximar; durante esse período, deixou de ser observado o sistema de duplo leilão que em regra é adotado nas Bolsas de Valores, interrompendo-se a continuidade do mercado que ele visa a assegurar.

Cabe ao Colegiado da CVM decidir, à vista do relatório do inquérito, das razões de defesa apresentadas e das informações pelo Banco Central do Brasil, se:

a) os servidores do Banco Central do Brasil, ao venderem aquela quantidade de ações, violaram o artigo 19 da Lei ํㅜㄴ.385, sobre registro de distribuição de emissão; 
b) a venda foi realizada com infração das normas adotadas pelas Bolsas de Valores em cumprimento à Circular no 303 da CVM e, em caso afirmativo, quais os responsáveis por essa infração;

c) a venda foi realizada com o propósito - da corretora ou dos servidores do Banco Central do Brasil - de criar condições artificiais de demanda, oferta ou preço das ações;

d) as condições em que foram vendidas as ações no final do pregão do dia 11 caracterizam infração às normas e práticas das Bolsas de Valores e, em caso afirmativo, quais os responsáveis por essa infração;

e) houve vazamento no mercado da informação da venda das ações pelo Banco Central do Brasil, em condições de permitir que os investidores do mercado tenham negociado na posse de informação privilegiada.

\subsection{0 artigo 18 da Lei n $.6 .385 / 76$}

Alegou-se que, sendo o Tesouro Nacional acionista controlador da Cia. Vale do Rio Doce, a venda de tal quantidade de ações configuraria distribuição de emissão secundária, sujeita, nos termos do $\S 2^{\circ}$, do art. 19 da Lei no ${ }^{\circ} .385$, a prévio registro na CVM.

Como demonstra a Superintendência Jurídica em parecer de fls. 1364, o dispositivo legal citado não tem aplicação à hipótese por se tratar de venda em bolsa.

A Lei 6.385 instituiu, como instrumento de fiscalização do mercado, três registros diferentes: (a) de distribuição de emissão mediante oferta pública (art. 19), (b) de negociação em bolsa (art. 21, I) e (c) de negociação no mercado de balcão (art. 21, II).

O primeiro é próprio das emissões primárias no mercado principal de valores, mas a lei o estende às emissões secundárias (por acionista controlador ou "underwritter") porque de outro modo o requisito do registro poderia ser facilmente elidido; mas ele somente tem aplicação quando há oferta pública de títulos, tal como definida no $\S^{\circ}$ do art. 19 , que não se confunde com venda em Bolsa. A função desse registro é (a) proteger os investidores do mercado de emissões irregulares, (b) assegurar informações sobre a companhia emitente, os valores oferecidos, o destino dos recursos e a remuneração dos intermediários, e (c) permitir a fiscalização dos métodos de promoção de venda. 
O registro de bolsa habilita a companhia a ter seus títulos negociados no pregão de Bolsa. É condição desse registro que a companhia mantenha o público investidor informado de todos os fatos que possam influir nas cotações dos seus títulos, e todas as companhias registradas estão sob permanente fiscalização das Bolsas e da CVM. Essas circunstâncias, assim como as condições em que se processam as operações de bolsa, tornam sem qualquer sentido a exigência de novo registro para que o acionista controlador possa vender ações de sua propriedade. Por isso, o registro de bolsa habilita à negociação todas as ações da companhia registrada, e não apenas as dos acionistas minoritários.

O registro de bolsa é suficiente para proteger todos os interesses do público investidor, e a companhia registrada em bolsa somente está sujeita ao registro ao art. 19 em caso de distribuição de emissão mediante oferta pública. A única hipótese em que há necessidade de proteção adicional dos investidores é o de negociação de lotes com características especiais, que modifiquem a configuração do mercado. Neste caso, a negociação deve - de acordo com as normas expedidas pelas Bolsas em cumprimento à Circular CVM no 303 - observar procedimentos especiais para assegurar a prévia informação do mercado e o ajustamento da demanda a uma oferta excepcional; mas esses procedimentos são exigidos de qualquer lote, seja qual for o proprietário das ações - acionista controlador ou minoritário, órgão público ou particular.

\subsection{Venda de grande lote sem adoção de procedimento especial}

Os fatos provados no processo não deixam dúvida que a venda das ações da Vale em questão foi executada com infração da exigência de procedimento especial prevista no item 10 da Circular no 303 da CVM. Cabe verificar, portanto, quais os responsáveis por essa infração.

\subsection{Natureza das normas expedidas pelas Bolsas de Valores em cumprimento à Circular n? 303}

Para isso é necessário precisar a natureza da norma infringida e seus destinatários, a fim de que sejam evitadas confusões conceituais na apreciação da matéria. 
A Lei 6.385, tal como a 4.728, adotou a orientação de descentralizar as funções de disciplina do mercado, admitindo a atribuição à Bolsa, por delegação, de funções normativas, de fiscalização dos seus membros e das companhias abertas, e de aplicação de sanções. Por isso, a Bolsa e suas operações são reguladas por normas de diversas hierarquias: (a) legais, (b) estabelecidas pelo Conselho Monetário Nacional e pela CVM (Lei 6.385, art. 18, itens I e II), ou (c) criadas pelos próprios órgãos da Bolsa. E estas últimas podem ser (I) fundadas no seu poder normativo interno, como associação civil, ou (II) expedidas no exercício de funções delegadas do poder público, como órgão auxiliar da CVM.

Esse já era o regime ao tempo da Lei 4.728, quando o Conselho Monetário aprovou a Res. nº 39 (que ainda hoje regula as Bolsas) que atribui aos órgãos da Bolsa amplas funções normativas, mas reservou ao poder público as seguintes atribuições:

Art. 20. Reservar-se-á ao Banco Central o direito de:

II - suspender a execução de normas adotadas pelas Bolsas de Valores, porém inadequadas ao seu bom funcionamento, e determinar a adoção daquelas que considere necessárias.

A Circular 303 da CVM consolidou diversas normas que já se acham em vigor, renovando às Bolsas a determinação de adotá-las. Não é, portanto, norma geral, mas ordem administrativa, com fundamento no art. 20 da Res. 39/66, para que as Bolsas adotassem as normas nela contidas. A BVRJ adotou essas normas transmitindo a Circular 303 a todos os seus membros. Por conseguinte, a exigência de sistema especial de negociação de lotes excepcionais estava e continua em vigor por força de normas criadas pela própria Bolsa; essas normas são de direito público, porque expedidas pela Bolsa no exercício de funções delegadas do poder público; e seu infrator está sujeito às sanções da Lei 6.385, aplicadas pela Bolsa ou pela CVM.

\subsection{Importância dessas normas para a confiabilidade do mercado}

O modelo econômico em que se baseia o funcionamento do mercado de bolsa está estruturado em torno de um mecanismo de "duplo leilão", desenvolvido em um mercado no qual todos os vendedores e compradores se 
irão conjugar e chegar a um preço de uma determinada ação através de livre competição de ofertas de compra e venda.

Quando se apresenta à venda um lote de volume historicamente anormal de uma certa ação, impõe-se a adoção de métodos e práticas especiais de negociação, como processo capaz de garantir a plena informação aos investidores, assegurando a continuidade do mercado e impedindo flutuações extremas de preços, uma vez que permitirá à demanda adaptar-se à nova e diversa configuração do mercado daquele mesmo ativo financeiro.

Sem a adoção desses métodos e práticas previstas no item 10 da Carta Circular 303, a profunda e repentina alteração de uma das forças atuantes no mercado terá como consequência uma flutuação brusca de preços, em detrimento do interesse público.

O mesmo ocorre no caso de venda parcelada de grandes lotes de ações: alterada, ainda que no curso do tempo, a configuração de uma das forças atuantes do mercado (a oferta de títulos), faz-se indispensável que, através de um adequado nível de informações, a força oposta (a demanda de títulos ofertados) tenha a oportunidade de se adequar às novas condições da força alterada.

$\mathrm{Na}$ venda parcelada, em sigilo, de um lote excepcional de ações, o vendedor se aproveita da ignorância do mercado para tentar obter um preço médio superior ao que alcançaria na venda em bloco. Os investidores do mercado que compram ações no início do processo de venda, enquanto a pressão de venda não se refletir nas cotações, são prejudicados.

\subsection{Alegação de inexequibilidade das normas}

A alegação da defesa de que as normas expedidas em cumprimento à Carta Circular 303 eram inexequíveis é improcedente.

A prova de que são exequíveis é que depois da repercussão do caso Vale foram observadas em diversas operações, de valor superior, inclusive, ao da venda das ações da Vale.

Além do mais, a própria Bolsa de Valores já puniu a corretora por infringência à mencionada Circular, antes da ocorrência deste episódio. 


\subsection{Destinatários das normas}

A matéria objeto dessas normas é método de negociação no pregão da Bolsa, onde somente têm acesso os representantes de corretoras e funcionários da Bolsa. Estes são, portanto, os únicos destinatários das normas e seus possíveis infratores. Como já reconheceu a Superintendência Jurídica em parecer de 5.2.78, os comitentes de ordens cumpridas no recinto da bolsa com inobservância dessas normas não estão sujeitos a sanções porque cabe às corretoras e à administração da Bolsa velar pela sua observância, e não aos investidores do mercado.

\subsection{Responsabilidade da Corretora}

Alega a Corretora que cumpriu ordens do Dedip que lhe recomendou sigilo, e que não conhecia o volume total da ordem.

O Banco Central do Brasil confirma que a ordem de venda foi dada nessas condições, mas essa confirmação não exclui a responsabilidade da corretora, que tem o dever de observar os métodos e práticas do mercado e não pode descumpri-los, ainda que para atender a pedido de autoridade pública.

A corretora não se acha subordinada ao Dedip e, ainda que esse não fosse o caso, a subordinação não justificaria a infração das normas que regem o mercado, porque até mesmo subordinado tem o dever de não cumprir ordens ilegais.

A primeira obrigação do intermediário é para com o mercado em geral, isto é, com o interesse público, e secundariamente para com seu cliente.

As corretoras detêm o privilégio da autorização para exercer a atividade com exclusividade nas Bolsas de Valores. A contrapartida deste privilégio é resguardar e assegurar a confiabilidade do mercado através da sua contribuição para manter este mercado disciplinado.

A ordem inicial de 35.000 .000 de ações, recebida pela corretora, já impunha adoção de sistema especial de negociações, mormente sabendo ela que haveria outras ordens posteriores. $\mathrm{O}$ volume das ordens recebidas na última meia hora do pregão do dia 11 também já seria suficiente, por si só, para que pedisse à administração da bolsa leilão especial.

O dever de sigilo, imposto pela lei, existe para proteger o interesse legítimo dos comitentes, e não poderia nunca servir de pretexto para que o corretor infrinja os métodos e práticas do mercado. 
A corretora tinha o dever de informar o Dedip que não podia cumprir a ordem nas condições pedidas, o que não fez, e se o Dedip insistisse, tinha o dever de recusar a ordem.

A corretora, tendo deixado de comunicar previamente à BVRJ a negociação do grande lote de ações, frustrou esta entidade na sua capacidade de cumprir bem o seu papel de acionar o mecanismo especial de venda, permitindo a criação do tumulto do pregão por todos reconhecido que pôs em risco a confiabilidade do mercado, como veremos mais adiante.

\subsection{Responsabilidade da Bolsa de Valores}

Não é possível deixar de considerar, conforme já expunha o BVRJ em sua carta Supge 124/80, que a adoção de mecanismos especiais de negociação se viu frustrada em razão de a bolsa, conforme já referido neste voto, não ter tido conhecimento antecipado de que se iria negociar um lote de ações de características peculiares, pelo seu volume.

Além disso, e segundo consta da bem armada defesa da BVRJ, seus Superintendentes Executivos, tanto quanto lhes permitia o nível de informação de que presumivelmente dispunham, acompanharam a evolução dos negócios, podendo quando muito questionar-se o acerto das decisões tomadas no sentido de não suspender as negociações, sendo de se reconhecer, no entanto, que no final do pregão do dia 11 de março - quando ocorreu o grande tumulto -, dado o inusitado volume negociado em tão curto espaço de tempo, seria impossível aos membros do corpo executivo da bolsa a tomada de qualquer providência eficaz.

Não obstante, surge clara a situação singular do Presidente da BVRJ, executor dos grandes lotes responsáveis pelo tumulto no mercado, que se omitiu completamente, não permitindo que a instituição por ele dirigida utilizasse os mecanismos operacionais apropriados às negociações de lotes volumosos, como tem feito sempre que é devidamente comunicada pelo intermédio da sua existência, fato amplamente comprovado pelas múltiplas e quase diárias ocorrências trazidas ao conhecimento da CVM, nas quais se fizeram respeitar integralmente os métodos e práticas de mercado consubstanciados na Carta-Circular PTE/303/78. 


\subsection{Violação da Instrução CVM n! $08 / 79$}

Essa instrução proíbe a qualquer participante do mercado - sem exclusão dos servidores de órgãos públicos - a criação de condições artificiais de demanda, oferta ou preço de valores mobiliários.

Condições artificiais são aquelas criadas em decorrência de negociações pelas quais seus participantes ou intermediários, por ação ou omissão dolosa, provocam, direta ou indiretamente, alterações no fluxo de ordem de compra e venda de ações (letra "a", inciso II da Instrução no ${ }^{\text {8) }}$.

Toda venda de grande lote de ações pode acarretar em uma pressão sobre os preços da cotação.

Resta examinar neste episódio se a depressão dos preços ocorreu por vontade de qualquer das partes, uma vez que é indispensável haver o intuito doloso por parte do agente para se configurar a infração à Instrução CVM no $08 / 79$.

\subsection{Responsabilidade da Corretora}

O relatório do inquérito com base nos fatos até então apurados concluiu que a corretora exerceu pressão de venda com o fim de provocar a baixa da cotação de ações da Vale, em seu benefício, porque estava com elevado prejuízo potencial na posição vendida no mercado futuro por parte de suas sociedades a ela ligadas. As provas circunstanciais autorizavam essa conclusão, mas a corretora em sua defesa afirmou que a pressão de venda no dia 11 resultou de ter recebido ordens do Bacen para liquidar todo o lote naquele dia, o que foi confirmado pelo Banco Central, que não desejava permanecer no mercado por mais tempo. Essa confirmação invalida a prova circunstancial de ação dolosa da corretora.

\subsection{Responsabilidade dos Servidores do Banco Central}

A infração à instrução poderia ter sido praticada pelos servidores do Banco Central que deram execução à decisão de vender as ações. Nas informações prestadas a fls. 1342, o Sr. Presidente do Banco Central declara que a venda em questão não foi executada com a intenção de criar condições 
artificiais de mercado, e que a ordem para a venda do maior volume de ações no final do pregão do dia 11 decorreu da decisão de o Banco Central retirar-se do mercado, interrompendo as vendas que vinham sendo realizadas.

Como já destacado, a infração à Instrução $n^{\circ}$ 08/79 pressupõe dolo, e à vista da declaração do Sr. Presidente do Banco Central há que excluir-se a hipótese de que os servidores daquela autarquia que transmitiram as ordens de venda tenham agido dolosamente.

\subsection{O pregão do dia 11}

Não resta dúvida que o tumulto verificado no pregão do dia 11 foi causado pelo volume inusitado de ordens de venda das ações da Vale. Tal fato poderia ter sido evitado se a Corretora intermediária das ordens administradas pelo próprio Presidente da Bolsa do Rio de Janeiro tivesse observado as normas e práticas de mercado solicitando a administração da BVRJ o apregoamento da venda através de leilão especial.

Por outro lado, o inquérito demonstrou que o operador da corretora, com o intuito de cumprir as ordens do cliente, descumpriu normas do pregão quando assumiu atitude inteiramente passiva, contribuindo para que não houvesse o "duplo leilão" e atuando sempre de forma a deixar evidente o volume inusitado do lote que possuía.

Procedeu o Sr. Jorge Salgado, assim, de modo análogo (e igualmente censurável) ao de seu colega e atuante na Bovespa por conta da mesma Corretora, em igual período, tendo sido este último censurado por aquela bolsa de valores pelo atentado às normas de apregoamento.

Não se pode aceitar a tese de que o operador assim agiu por comando de seu chefe. Os operadores têm os próprios deveres e responsabilidades mais importantes que a submissão a ordens de seus superiores.

\subsection{Informação privilegiada}

$\mathrm{Na}$ fase do inquérito foram procedidos levantamentos e apurações relativamente aos compradores das ações no final do pregão do dia 11, concluindo-se pela inexistência de indícios de que esses compradores tenham sido favorecidos por informação privilegiada sobre a quantidade de ações que 
estavam sendo vendidas e o preço mínimo estabelecido pelo Dedip. Os maiores compradores foram investidores habituais do mercado, independentemente de informação privilegiada, de que uma grande quantidade de ações da Vale estava entrando no mercado e os únicos aptos a aproveitarem a oportunidade para adquirirem as ações quando essas atingiram nível de cotação que consideravam vantajoso.

\section{Conclusões}

Isto posto, fica claro que houve por parte da Corretora Ney Carvalho, de seu administrador e Presidente da Bolsa de Valores do Rio de Janeiro, Sr. Fernando Souza Ribeiro de Carvalho, e do seu operador, Sr. Jorge Salgado, flagrante descumprimento às normas e práticas de mercado, adotadas pelas bolsas em cumprimento à Carta Circular 303, atentando contra os princípios de confiabilidade do mercado e do interesse público que cabe também aos intermediários e seus prepostos preservar.

A situação do Sr. Fernando Souza Ribeiro de Carvalho na dupla função de administrador da corretora e Presidente da Bolsa, apesar de não ter agido com o intuito de beneficiar a corretora ou pessoas a ele ligadas, fica agravada pelo fato de ele conhecer a fundo os princípios que embasam a necessidade de as vendas e grandes lotes serem feitos através de mecanismos especiais.

Somente por reconhecer que na cultura brasileira de mercado - que precisa ser alterada - sempre foi considerado que as ordens dos clientes, especialmente do Governo, não são para ser discutidas, mas sim cumpridas, é que deixo de puni-lo com a multa pecuniária máxima.

Assim sendo, em conformidade com o artigo 11 da Lei no 6.385/76, sou pela aplicação da multa de 400 (quatrocentas) ORTN ao Sr. Fernando Carvalho, na qualidade de Presidente do Conselho de Administração da Bolsa de Valores do Rio de Janeiro, por descumprimento dos seus deveres regimentais e regulamentares.

Inclino-me, também, pela aplicação da pena de advertência ao Sr. Fernando Carvalho como administrador da Corretora Ney Carvalho e à Corretora Ney Carvalho S.A. pelo descumprimento das normas e práticas do mercado.

Sou ainda pela aplicação de penalidade de advertência ao Sr. Jorge Salgado pelo seu comportamento atentatório às práticas do pregão, verificado no final do pregão do dia 11 de março de 1980. 
Pelos motivos antes expostos não acolho as demais sanções propostas pelo encarregado do inquérito.

É o meu voto. 